\title{
Invitro and Invivo Inhibition of Metyrapone Metabolism by Glycyrrhetinic Acid in Male Wistar Rats
}

\begin{abstract}
Objectives: We investigated the inhibitory effect of glycyrrhetinic acid (GA), an $11 \beta$-hydroxysteroid dehydrogenase type 1 (11B-HSDI) inhibitor, on the reductive metabolism of metyrapone (MP) in an invitro study, and the effect of the co-administration of GA on the pharmacokinetics of MP and its metabolites in rats.

Methods: High-performance liquid chromatography was used to determine the metabolic activities of MP in the liver and testis and the plasma concentrations of MP and its metabolites after MP with or without a GA dose to rats.

Results: GA strongly inhibited the reduction of MP to metyrapo (MPOL) in the microsomal and mitochondrial fractions of both the tissues in a dose-dependent manner. When GA was co-administrated, the plasma levels of MPOL and MPOL N-oxide II (MPOL NOII) were lower than those of MP alone, while the levels of MP and MP NOIl were higher than those of MP alone.

Conclusion: The invitro GA inhibition suggests that the reduction of MP in the rat liver and testis is catalyzed by $11 \beta-H S D 1$. The coadministration of GA modulated the plasma pharmacokinetics of MP, MPOL, MP NOII and MPOL NOIl, suggesting that the changes in the pharmacokinetics were caused by the inhibition of $11 \beta$-HSDI invivo.

Keywords: Metyrapone; 11ß-hydroxysteroid dehydrogenase 1; Male rats; Liver; Testis; Invivo drug-drug interaction
\end{abstract}

\section{Introduction}

$11 \beta$-hydroxysteroid dehydrogenase (11 $\beta$-HSD) belongs to the short-chain dehydrogenase/reductase super family, and plays an important role in the reduction of ketone groups of various drugs [1-3]. Two isozymes of $11 \beta-H S D, 11 \beta-H S D$ type1 (11 -HSD1) and $11 \beta$-HSD type $2(11 \beta$-HSD2), are known, and distributed in a variety of tissues $[3,4]$. For 11 $\beta$-HSD1, high expression levels are observed in the liver, reproductive organs and adipose tissue, with high levels of $11 \beta$-HSD2 in the kidney and colon $[5,6]$. Overall, the enzymes are located in the microsomal fraction of the tissues, in which $11 \beta$-HSD 1 and $11 \beta$-HSD2 have NADP(H)-dependent glucocorticoid 11-oxidoreductase activity and $\mathrm{NAD}^{+}$-dependent glucocorticoid 11 -hydroxydehydrogenase activity, respectively $[1,6,7]$. It has been reported that a higher expression of $11 \beta-\mathrm{HSD} 1$ in the adipose tissue increases endogenous cortisol concentrations, resulting in the development of Cushing's syndrome [8,9].

Metyrapone (MP) (Figure 1) is employed as a therapeutic drug for the treatment of Cushing's syndrome, because the drug suppresses cortisol biosynthesis by inhibiting 11ß-hydroxylase activity [10]. MP which contains a ketone group is reduced to a secondary alcohol metabolite, metyrapol (MPOL) (Figure 1). Our recent study [11] demonstrated that, after a single oral administration of MP to male Wistar rats, MPOL was the major metabolite and its concentration was maintained at levels higher than these for MP in

\section{Journal of}

Pharmaceutics \& Pharmacology

\author{
Hideyuki Murata ${ }^{1,2}$, Toshiyuki Higuchi2 ${ }^{*}$ and Masaki \\ Otagiri ${ }^{3}$ \\ ${ }^{1}$ Department of Pre-clinical, Janssen Pharmaceutical K.K, 5-2, \\ Nishi-kanda 3-chome, Chiyoda-ku, Tokyo 101-0065, Japan \\ ${ }^{2}$ Department of Health Biosciences, Nihon Pharmaceutical \\ University, 10281 Komuro, Ina-machi, Kitaadchi-gun, Saitama 362- \\ 0806, Japan \\ ${ }^{3}$ Faculty of Pharmaceutical Sciences, Sojo University, 4-22-1 Ikeda, \\ Nishi-ku, Kumamoto 860-0082, Japan

\section{Address for Correspondence} \\ Toshiyuki Higuchi, Department of Health Biosciences, Nihon \\ Pharmaceutical University, 10281 Komuro, Ina-machi, Kitaadachi- \\ gun, Saitama 362-0806, Japan, Tel: +81-48-721-1155; Fax: +81-48- \\ 721-6718; E-mail: higuchi@nichiyaku.ac.jp \\ Submission: 01 November, 2016 \\ Accepted: 12 December, 2016 \\ Published: 19 December, 2016 \\ Copyright: () 2016 Murata $\mathrm{H}$ et al. This is an open access article \\ distributed under the Creative Commons Attribution License, which \\ permits unrestricted use, distribution, and reproduction in any medium, \\ provided the original work is properly cited.
}

plasma. The major site involved in the reduction to MPOL in the rats is the liver, and the high MP reducing activity is presented in the liver microsomal fraction [11]. Additionally, we previously reported that the rat liver MP-reducing enzyme is present in not only the microsomal fraction but also the mitochondrial fraction [11]. Since many drug-metabolizing enzymes including reductase activity for ketone-containing drugs are present in the mitochondrial fraction [12], we hypothesized that the rat mitochondrial fraction plays a role in the reduction of MP in addition to the microsomal fraction. Furthermore, we proposed that the major enzyme involved in reduction of MP to MPOL is $11 \beta-\mathrm{HSD} 1$ in both subcellular fractions similar to the human liver [11]. Therefore, it is conceivable that the

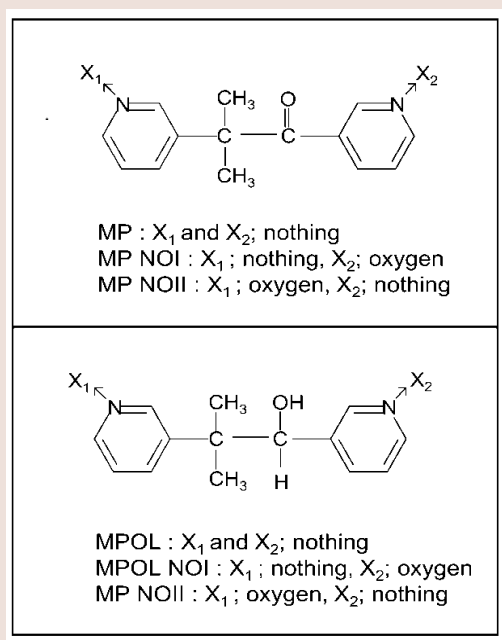

Figure 1: Structures of MP and its metabolites. 
Citation: Murata H, Higuchi T, Otagiri M. Invitro and Invivo Inhibition of Metyraponemetabolism by Glycyrrhetinic Acid in Male Wistar Rats. J Pharmaceu Pharmacol. 2016;4(1): 6.

rats area relevant species for evaluating human subjects in predicting the involvement of $11 \beta$-HSD1 in these metabolic steps. Interestingly, high MP reduction activity was found in both fractions derived from rat testis [11]. However, the enzyme involved in this conversion in this tissue is not well understood.

The metabolizing enzyme activity of a drug is often modulated by the co-administration of inhibitors or inducers that affect the drug-metabolizing enzyme. Therefore, the prediction of drug-drug interactions related to the drug metabolism in humans is typically examined in an invitro metabolism study of tissue subcellular fractions or in invivo pharmacokinetic studies using experimental animals. The most important enzyme in drug metabolism, cytochrome P450s (CYPs), is involved in metabolic interactions with other drugs. MP has been used since a long time ago as an CYP inhibitor in invitro and invivo studies in the rats $[13,14]$. As described above, although it was suggested that $11 \beta$-HSD 1 contributes to the reductive metabolism of MP to MPOL, in so far we know, there is no report of drug-drug interactions towards the metabolism of MP by an $11 \beta$-HSD1 inhibitor. Therefore, it is not clear whether the inhibitor affects the pharmacokinetics of MP and its metabolites. Of the known $11 \beta$-HSD1 inhibiters $[15,16]$, we focused our attention on glycyrrhetinic acid (GA) and examined its effect on the metabolism of MP in the rat liver and testis invitro and the pharmacokinetics invivo.

The finding reported here in provide new evidence to show that the use of GA as an inhibitor of $11 \beta-H S D 1$ is related to the reduction of MP to MPOL in the microsomal and mitochondrial fractions of the testis as well as the liver in male Wistar rats. In addition, we show the first time, that the pharmacokinetics of MP and its metabolites are modulated by the co-administration of GA to the rats.

\section{Materials and Methods}

\section{Chemicals}

MP and glycyrrhetinic acid (GA) were purchased from SigmaAldrich (Tokyo, Japan). Five metabolites of MP, MPOL, the form in which either of two pyridyl nitrogen atoms, MP $N$-oxide I (MP NOI) and MP N-oxide II (MP NOII), and the form in which the ketone group is reduced, MPOL $N$-oxide I (MPOL NOI) and MPOL $N$-oxide II (MPOL NOII) (Figure 1) were synthesized according to our previous report [11]. NADP ${ }^{+}$, glucose-6-phosphate (G-6-P) and glucose-6-phosphate dehydrogenase (G-6-PDH) were purchased from Oriental Yeast Co., Ltd. (Tokyo, Japan). Magnesium chloride $6 \mathrm{H}_{2} \mathrm{O}$ was purchased from Nacalai tesque (Tokyo, Japan). Highperformance liquid chromatography (HPLC) grade methanol and Milli-Q water were used to prepare the mobile phase for the HPLC analyses. All chemicals and solvents were commercial grades of highest purity or HPLC grade.

\section{Animals}

Male Wistar rats (9 weeks old, 200-240 g) were purchased from Japan SLC Inc., (Shizuoka, Japan). All animal experiments were approved by the Animal Experimentation Ethics Committee in Nihon Pharmaceutical University (permit numbers: 15-11; 24-September-2015, 15-15; 5-October-2013), and performed in accordance with the Guidelines for Animal Experimentation of Nihon Pharmaceutical University.

\section{Preparation of subcellular fractions}

Blood from rats which were not administered MP and GA was withdrawn any from the abdominal aorta. The livers perfused with ice-cold $1.15 \% \mathrm{KCl}$ and the testis were isolated and homogenized in three volumes of homogenization buffer, $10 \mathrm{mM}$ phosphate buffer ( $\mathrm{pH}$ 7.4) containing $1.15 \% \mathrm{KCl}$ using a glass-Teflon Potter Elvenhjem homogenizer (Iwaki Glass Co. Ltd., Tokyo, Japan). All subsequent procedures were performed at $4{ }^{\circ} \mathrm{C}$. The mitochondrial and microsomal fractions were prepared based on our previous report [11].

\section{MP-metabolizing enzyme assays}

For the assay of MP reductase and oxidase activities, the reaction mixture consisted of an MP solution (final concentration: $1 \mathrm{mM}$ ), an enzyme solution (mitochondrial and microsomal fractions), an NADPH generating system (final concentration: $1.3 \mathrm{mM} \mathrm{NADP}+, 3.3$ mM G-6-P, 0.4 units/mL G-6-PDH, $3.3 \mathrm{mM} \mathrm{MgCl}_{2}$ ) and $100 \mathrm{mM}$ $\mathrm{Na}-\mathrm{K}$ phosphate buffer ( $\mathrm{pH}$ 7.4). The enzyme solution was added to a one tenth volume of the reaction mixture. Various concentrations of GA (final concentrations: 0.005-1 $\mu \mathrm{M}$ ) were dissolved in ethanol (final concentration: less than $2 \%$ ), and were added to the reaction mixtures before preincubation for five min at $37^{\circ} \mathrm{C}$. After preincubation, an MP solution was added to the reaction mixture. The reactions were terminated by adding 2 volumes of methanol containing 3-benzoylpridine as an internal standard (IS) after 60 min and the mixtures were then cooled on ice for $30 \mathrm{~min}$. After centrifugation $\left(20,630 \mathrm{~g}\right.$ for $5 \mathrm{~min}$ at $\left.4{ }^{\circ} \mathrm{C}\right)$, the solutions were filtered using a Cosmonice filter $S$ (pore size; $0.45 \mu \mathrm{m}$, filter diameter; $4 \mathrm{~mm}$; Nacalai tesque, Tokyo, Japan) for HPLC analysis. Specific activities of the enzyme in the subcellular fractions were expressed as nanomoles of MP metabolites formed per min per mg of protein. Protein concentrations were determined by the Bicinchoninic acid method with bovine serum albumin as the standard [17].

\section{Drug administration and sample preparation}

The co-administration of GA to male rats was based on the method of Lin et al. [18]. The rats were divided into two groups and administered intraperitoneally with GA at a dose of $10 \mathrm{mg} / \mathrm{kg}$ or vehicle three times before MP dosing. The rats were fasted overnight before MP administration. After dissolving the MP in 5\% glucose, the resulting MP solution to rats was administered at a single oral dose of $50 \mathrm{mg} / \mathrm{kg}$. Whole blood samples were obtained from the abdominal aorta at $0.25,0.5,1,2,4$, and $6 \mathrm{~h}$ after MP dosing and were immediately drawn into heparinized test tubes. Plasma samples were obtained by centrifugation $\left(3,000 \mathrm{~g}\right.$ for $10 \mathrm{~min}$ at $\left.4{ }^{\circ} \mathrm{C}\right)$ of the blood samples and were stored at $-80^{\circ} \mathrm{C}$ until used in an analysis. The plasma $(200 \mu \mathrm{L})$ was deproteinized by adding methanol containing IS $(400 \mu \mathrm{L})$, and the mixtures allowed to stand for $30 \mathrm{~min}$ at room temperature. The HPLC samples were prepared by the same method as for the enzyme assay.

\section{HPLC-ultraviolet (HPLC-UV) analysis}

The HPLC-UV conditions were the same as used in our previous report [11]. Calibration curves were constructed by plotting the peakheight ratio of MP and its metabolites to that for IS in the range of 
Citation: Murata H, Higuchi T, Otagiri M. Invitro and Invivo Inhibition of Metyraponemetabolism by Glycyrrhetinic Acid in Male Wistar Rats. J Pharmaceu Pharmacol. 2016;4(1): 6.

1.13 - $90.0 \mathrm{ng} / \mathrm{mL}$ (MPOL; 4.93-394 nmol/L, MP NOI and MP NOII; 4.64-372 nmol/L, MPOL NOI and MPOL NOII; 4.61-368 nmol/L). The lower limit of quantification (LLOQ) was defined as the lowest concentration on the calibration curve. The data were collected and analyzed using GL Science software.

\section{Pharmacokinetics analysis}

The pharmacokinetic parameters of MP and its metabolites were estimated by a non-compartmental analysis were calculated using Phoenix WinNonlin (version 6.3, Pharsight, Mountain View, $\mathrm{CA})$. The estimated parameters included the area under the plasma concentration-time curve from time 0 to $6 \mathrm{~h}\left(\mathrm{AUC}_{6 \mathrm{~h}}\right)$, the area under the plasma concentration-time curve from time zero to infinite time $\left(\mathrm{AUC}_{\infty}\right)$ and the elimination half-life $\left(\mathrm{t}_{1 / 2}\right)$ were determined. In addition, maximum plasma concentration $\left(\mathrm{C}_{\text {max }}\right)$ and the time to reach the peak plasma concentration $\left(\mathrm{t}_{\max }\right)$ were also determined.

\section{Statistics}

Data are presented as the mean value and standard deviation of the mean. In invitro MP metabolism, $\mathrm{IC}_{50}$ (concentration of inhibitor producing $50 \%$ inhibition in enzyme activity) for $11 \beta-H S D 1$ inhibition by GA was calculated using nonlinear regression. In the pharmacokinetics of MP and its metabolites after MP alone and the co-administration dose of GA, statistical analysis between the groups was assessed by means of unpaired Student's $t$ test. A $p$-value of $<0.05$ was considered statistically significant.

\section{Results}

\section{Inhibitory effects of GA on MP reduction activity in the liver}

Our recent invitro study on MP metabolism in Wistar male rats suggested that MP was efficiently reduced to MPOL in the presence of an NADPH generation system in the liver, and that reduction of MP to MPOL was catalyzed by $11 \beta$-HSD1 in microsomal and mitochondrial fractions [11]. The finding presented here in indicates that the $\mathrm{NADPH}$-dependent MP reduction activities in the liver microsomal and mitochondrial fractions were 4.08 and $0.76 \mathrm{nmol} / \mathrm{min} / \mathrm{mg}$ protein, respectively. When T0504 $(1 \mu \mathrm{M})$, a selective $11 \beta$-HSD1 inhibitor, was added to the reaction system to identify the existence of $11 \beta-H S D 1$ in both subcellular fractions, MPOL productions were inhibited by approximately $91 \%$ in both fractions (data not shown). Since T0504 is not drug but compound, we examined the issue of whether the reduction of MP in both subcellular fractions was inhibited by GA, a drug and a potent $11 \beta-H S D 1$ inhibitor (Figures $2 \mathrm{~A}$ and $2 \mathrm{~B}$ ). When various concentrations of GA were added to the reaction systems, microsomal reduction of MP to MPOL was inhibited in a dose-dependent manner with an $\mathrm{IC}_{50}$ value of $0.62 \mu \mathrm{M}$ (Figure 2A). Similarly, GA inhibited mitochondrial MP reduction activity with the $\mathrm{IC}_{50}$ value of $0.10 \mu \mathrm{m}$ (Figure $2 \mathrm{~B}$ ). These results suggest that reduction of MP to MPOL in both fractions in the liver were catalyzed by $11 \beta-H S D 1$, and that the inhibitory strength was higher in the mitochondrial fraction than in the microsomal fraction.

\section{Inhibitory effects of GA on MP reduction activity in the testis}

The rat testis was the secondary high tissue for the NADPHdependent MP reduction activities [11]. The activities in the microsomal and mitochondrial fractions were 2.96 and 0.83 $\mathrm{nmol} / \mathrm{min} / \mathrm{mg}$ protein, respectively. Both activities were inhibited approximately $90 \%$ by T0504 $(1 \mu \mathrm{M})$, suggesting that $11 \beta$-HSD 1 was located in the testis (data not shown). The inhibitory effects of GA against the reduction of MP to MPOL in the testis were investigated in the same manner as the liver (Figures $3 \mathrm{~A}$ and $3 \mathrm{~B}$ ). As shown in Figure 3, the testis microsomal and mitochondrial MP reductions

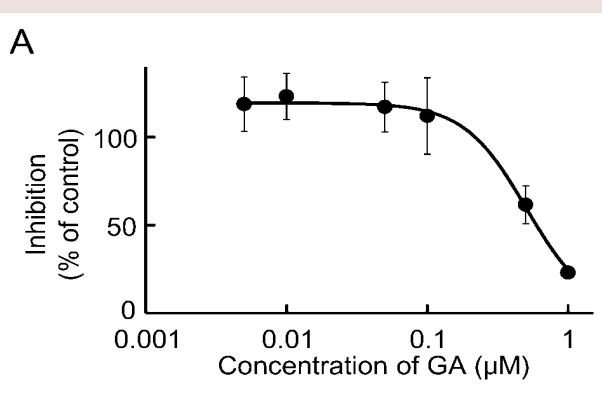

B

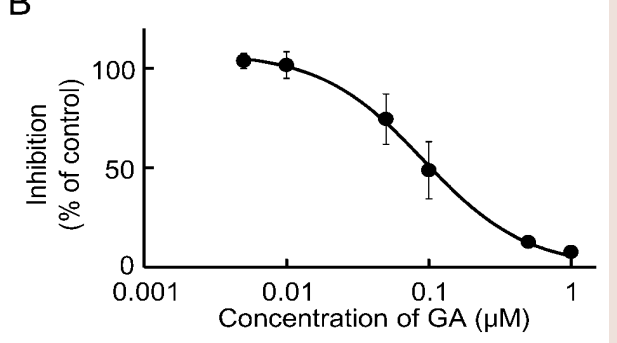

Figure 2: Inhibitory effect of GA on MP reduction activity in liver (A) microsomal and (B) mitochondrial fractions. Each data point represents the average of triple determinations and error bars represent the standard deviation. The solid line represents the fitted line obtained by a nonlinear regression analysis.

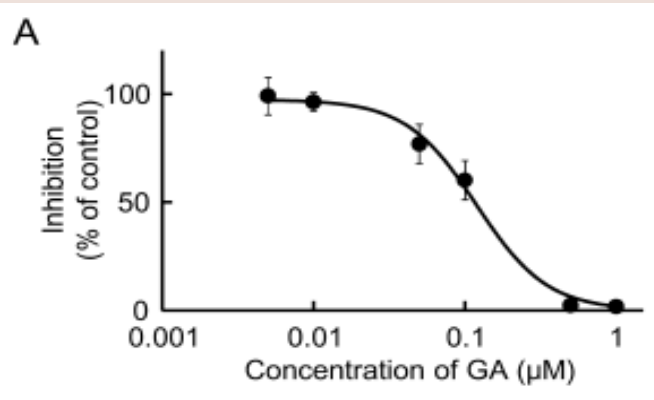

B

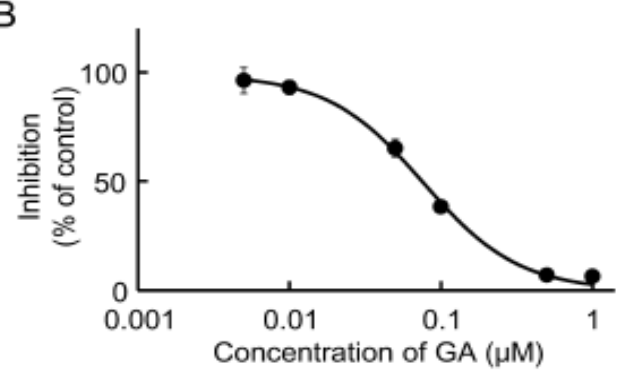

Figure 3: Inhibitory effect of GA on MP reduction activity in testis (A) microsomal and (B) mitochondrial fractions. Each data point represents the average of triple determinations and error bars represent the standard deviation. The solid line represents the fitted line obtained by a nonlinear regression analysis. 
Citation: Murata H, Higuchi T, Otagiri M. Invitro and Invivo Inhibition of Metyraponemetabolism by Glycyrrhetinic Acid in Male Wistar Rats. J Pharmaceu Pharmacol. 2016;4(1): 6.

ISSN: 2327-204X

Table 1: Pharmacokinetic parameters of MP and MPOL after the coadministration of MP and GA or vehicle to male rats.

\begin{tabular}{|l|c|c|c|c|}
\hline $\begin{array}{l}\text { Measured } \\
\text { substance }\end{array}$ & \multicolumn{2}{|c|}{ MP } & \multicolumn{2}{c|}{ MPOL } \\
\hline Dose & MP alone & $\begin{array}{c}\text { GA } \\
\text { combination }\end{array}$ & MP alone & $\begin{array}{c}\text { GA } \\
\text { combination }\end{array}$ \\
\hline $\mathrm{t}_{\text {max }}(\mathrm{h})$ & 0.25 & 0.25 & 2.00 & 4.00 \\
\hline $\mathrm{C}_{\text {max }}(\mathrm{ng} / \mathrm{mL})$ & 75.50 & 73.80 & 114.30 & 54.4 \\
\hline $\mathrm{t}_{1 / 2}(\mathrm{~h})$ & 1.29 & 2.26 & 3.15 & - \\
\hline AUC $_{6 \mathrm{~h}}(\mathrm{ng} \cdot \mathrm{h} / \mathrm{mL})$ & 130.81 & 295.19 & 431.15 & 211.65 \\
\hline $\mathrm{AUC}_{\infty}(\mathrm{ng} \cdot \mathrm{h} / \mathrm{mL})$ & 137.53 & 363.03 & 646.55 & - \\
\hline
\end{tabular}

MP was orally administered at a single dose of $50 \mathrm{mg} / \mathrm{kg}$. GA was intraperitoneally administered three times at a dose of $10 \mathrm{mg} / \mathrm{kg}$ before the MP dose. The pharmacokinetic parameters were calculated from mean plasma concentrations, n=3. -, not calculated.

Table 2: Pharmacokinetic parameters of MP NOII and MPOL NOII after the coadministration of MP and GA or vehicle to male rats.

\begin{tabular}{|c|c|c|c|c|}
\hline $\begin{array}{c}\text { Measured } \\
\text { substance }\end{array}$ & \multicolumn{2}{|c|}{ MP NOII } & \multicolumn{2}{c|}{ MPOL NOII } \\
\hline Dose & MP alone & $\begin{array}{c}\text { GA } \\
\text { combination }\end{array}$ & MP alone & GA combination \\
\hline $\mathrm{t}_{\text {max }}(\mathrm{h})$ & 2.00 & 2.00 & 4.00 & 4.00 \\
\hline $\mathrm{C}_{\max }(\mathrm{ng} / \mathrm{mL})$ & 19.40 & 38.80 & 31.30 & 18.90 \\
\hline $\mathrm{t}_{1 / 2}(\mathrm{~h})$ & 88.25 & 10.78 & - & - \\
\hline AUC $_{6 \mathrm{~h}}(\mathrm{ng} \cdot \mathrm{h} / \mathrm{mL})$ & 100.74 & 163.01 & 119.94 & 69.83 \\
\hline AUC $_{\infty}(\mathrm{ng} \cdot \mathrm{h} / \mathrm{mL})$ & 2494.41 & 629.53 & - & - \\
\hline
\end{tabular}

MP was orally administered at a single dose of $50 \mathrm{mg} / \mathrm{kg}$. GA was intraperitoneally administered three times at a dose of $10 \mathrm{mg} / \mathrm{kg}$ before the MP dose. The pharmacokinetic parameters were calculated from mean plasma concentrations, $\mathrm{n}=3-$, not calculated.

were inhibited by addition of GA, and these inhibitions were dosedependent, with an $\mathrm{IC}_{50}$ value of 0.13 and $0.07 \mu \mathrm{M}$, respectively. These results indicate that MP reduction is also inhibited by GA in the testis.

\section{Interaction with GA on the pharmacokinetics of MP and MPOL}

The effect of $11 \beta$-HSD1 inhibition by the co-administration of GA on the pharmacokinetics of MP and its metabolites in rats was investigated in an invivo study. Figure 4 and Table 1 show the plasma concentration profiles and the pharmacokinetic parameters for MP and MPOL after the administration of MP to rats, with or without GA, respectively. Since it is known that GA rapidly inhibits $11 \beta$-HSD1 in invivo studies $[18,19]$, the effect of the inhibition was evaluated for the periods of up to $6 \mathrm{~h}$ after the administration of MP. The co-administration of GA had no effect on the $\mathrm{C}_{\max }$ of MP at $0.25 \mathrm{~h}$ following an oral administration of MP, similar to MP alone, indicating that GA has no effect on the absorption of MP (Figure 4A and Table 1). After that, the $\mathrm{t}_{1 / 2}$ of MP was approximately double as the result of the co-administration of GA, and a statistically significant increase was observed in the concentration profile from $2 \mathrm{~h}$ onward after the MP dose (Figure 4A). Thus, relative to the AUC of MP alone $(130.81 \mathrm{ng} \cdot \mathrm{h} / \mathrm{mL})$, a 2.2 -fold increase in that of co-administration of GA (295.19 $\mathrm{ng} \cdot \mathrm{h} / \mathrm{mL}$ ) was observed (Table 1). On the other hand, the MPOL plasma concentration rapidly and significantly decreased as the result of the co-administration of GA compared with MP alone and then slowly increased within $4 \mathrm{~h}$ of $\mathrm{t}_{\max }$. The profile after $\mathrm{t}_{\max }$ was the almost the same as that for MP alone (Figure $4 \mathrm{~B}$ ). As shown in Table 1, the $\mathrm{C}_{\max }(54.4 \mathrm{ng} / \mathrm{mL})$ and $\mathrm{AUC}_{6 \mathrm{~h}}(211.65 \mathrm{ng} \cdot \mathrm{h} / \mathrm{mL})$ after the co-administration of GA decreased to one half the level of those after $\mathrm{MP}$ alone $\left(\mathrm{C}_{\max } ; 114.30 \mathrm{ng} / \mathrm{mL}\right.$ and $\left.\mathrm{AUC}_{6 \mathrm{~h}} ; 431.15 \mathrm{ng} \cdot \mathrm{h} / \mathrm{mL}\right)$.

\section{Interaction with GA on the pharmacokinetics of MPOL NOII and} MP NOII

Since GA caused variations in the pharmacokinetics of MP and MPOL, we also examined the issue of whether the pharmacokinetics
A

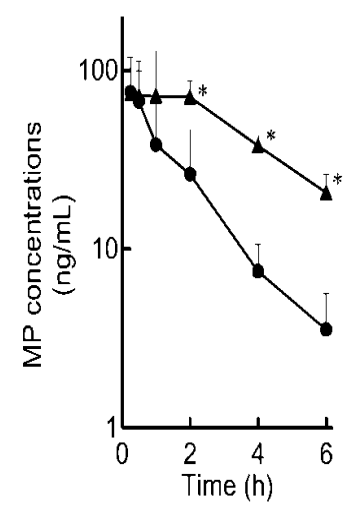

B

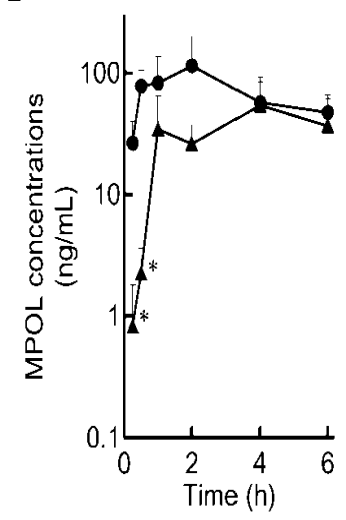

Figure 4: Plasma concentration profiles of (A) MP and (B) MPOL after the co-administration of MP and GA or vehicle to male rats. MP was orally administered at a single dose of $50 \mathrm{mg} / \mathrm{kg}$. GA was intraperitoneally administered three times at a dose of $10 \mathrm{mg} / \mathrm{kg}$ before the MP dose. Each data point represents the mean of three separate determinations and error bars represent the standard deviation. Asterisk $\left(^{*}\right)$ indicates significant differences compared to MP dose group at $p<0.05$. $\bullet$ MP alone; $\boldsymbol{\Delta}$, MP plus GA.
A

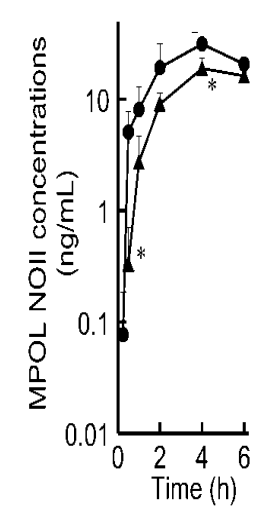

B

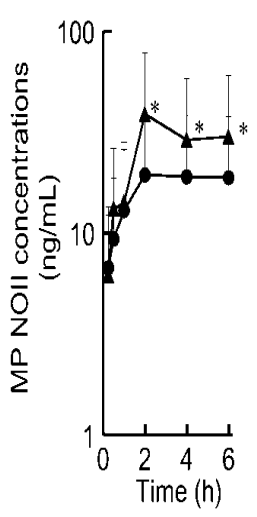

C

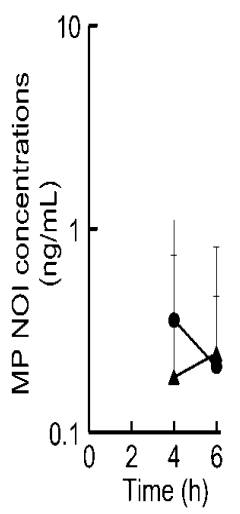

Figure 5: Plasma concentration profiles of (A) MPOL NOII, (B) MP NOII and (C) MP NOI after the co-administration of MP and GA or vehicle to male rats. MP was orally administered at a single dose of $50 \mathrm{mg} / \mathrm{kg}$. GA was intraperitoneally administered three times at a dose of $10 \mathrm{mg} / \mathrm{kg}$ before the MP dose. Each data point represents the mean of three separate determinations and error bars represent the standard deviation. Asterisk (*) indicates significant differences compared to the MP dose group at $p<0.05$. $\bullet$, MP alone; $\boldsymbol{\Lambda}$, MP plus GA. 
of other MP metabolites (MPOL NOI, MP NOI, MPOL NOII and MP NOII) were changed by the dose of GA. Figure 5 and Table 2 depict the plasma concentration profiles and the pharmacokinetic parameters of MP NOI, MPOL NOII and MP NOII after the administration of MP with or without GA to the rats, respectively. The pharmacokinetics of MPOL NOI was not evaluated, because the plasma concentrations were LLOQ in both dose groups for all sampling points (data not shown). In the GA co-administration group, a significantly lower profile of MPOL NOII was immediately observed after the MP dose, similar to the MPOL profile, resulting in an LLOQ at $0.25 \mathrm{~h}$ (Figure $4 \mathrm{~B}$ and $5 \mathrm{~A}$ ). Due to the slow increase in the plasma concentration of MPOL NOII by the co-administration of GA, a significant difference was also observed at $4 \mathrm{~h}$ after the MP dose, and the $\mathrm{C}_{\max }$ and $\mathrm{AUC}_{6 \mathrm{~h}}(18.90 \mathrm{ng} / \mathrm{mL}$ and $69.83 \mathrm{ng} \cdot \mathrm{h} / \mathrm{mL})$ were around one half compared with the values for the MP alone group (31.30 $\mathrm{ng} / \mathrm{mL}$ and $119.94 \mathrm{ng} \cdot \mathrm{h} / \mathrm{mL}$ ) (Figure 5A and Table 2). On the other hand, the co-administration with GA caused a statistically significant increase in the plasma concentration of MP NOII at 2 and $4 \mathrm{~h}$ after the MP dose (Figure 5B). The $\mathrm{C}_{\max }$ and $\mathrm{AUC}_{6 \mathrm{~h}}(38.80 \mathrm{ng} / \mathrm{mL}$ and 163.01 $\mathrm{ng} \cdot \mathrm{h} / \mathrm{mL}$ ) were around twice and 1.6 times higher than those of MP alone group (19.40 ng/mL and $100.74 \mathrm{ng} \cdot \mathrm{h} / \mathrm{mL}$ ), respectively (Table 2). On the other hand, GA had no observed effect on MP NOI plasma concentrations because of the low plasma concentration and large individual variability (Figure 5C).

\section{Discussion}

In this study, we demonstrated that the reduction of MP to MPOL, a major MP metabolite, was inhibited by GA, an inhibitor of $11 \beta$-HSD 1 , in the microsomal and mitochondrial fractions of the liver and testis in male Wistar rats, and that the plasma pharmacokinetics of MP and its metabolites were modulated by the co-administration of GA.

Our previous report provided evidence that suggested MPOL was produced mainly in the liver, in which the major enzyme was $11 \beta$-HSD1, based on the inhibitor sensitivities [11]. However, the effect of an 11 $\beta$-HSD1 inhibitor on MP reduction in the testis and the pharmacokinetics of MP remains unclear. Although it was reported that some drugs inhibit $11 \beta$-HSD1 [15,17], we focused on GA which has the strongest inhibitory effect of $11 \beta-H S D 1$ with a minimum concentration as a possible drug in combination with MP. Since GA strongly inhibits NADPH-dependent $11 \beta$-HSD1 activity in the liver and testis [19], which MPOL was mainly produced, the drug was a good compound for evaluating drug-drug interactions towards MP metabolism. Furthermore, male Wistar rats were a relevant species for use in predicting drug-drug interactions related to $11 \beta$-HSD1 in humans, because the primary enzyme for reduction of MP to MPOL is $11 \beta-H S D 1$ in the liver microsomal and mitochondrial fractions, similar to humans [11]. In the present study, the concentration of GA were determined based on the inhibition constant $\left(K_{\mathrm{i}}\right)$ for 11 $\beta$-HSD1dependent metabolism of cortisone to cortisol (active form) [15]. GA inhibited mitochondrial MP reduction activity $\left(\mathrm{IC}_{50}: 0.10 \mu \mathrm{M}\right)$ stronger than microsomal activity $\left(\mathrm{IC}_{50} ; 0.62 \mu \mathrm{M}\right)$ in the rat liver (Figures 2A and 2B). Similarly, microsomal and mitochondrial MP reductions from the testis samples were inhibited by $\mathrm{GA}\left(\mathrm{IC}_{50} ; 0.13\right.$ and $0.07 \mu \mathrm{M}$, respectively), suggesting that the testis enzyme involved in the reduction was also $11 \beta$-HSD1 (Figures $3 \mathrm{~A}$ and $3 \mathrm{~B}$ ). These IC $_{50}$ values were similar to $K_{\mathrm{i}}(0.44 \mu \mathrm{M})$ for GA against $11 \beta-\mathrm{HSD} 1$ activity [15]. Although GA inhibits NADPH-dependent 11 $\beta$-HSD1 and $\mathrm{NAD}^{+}$-dependent $11 \beta$-HSD2, which is highly expressed in the liver and kidney, respectively [1,5-7], taking into account the major tissues for its metabolism (liver and testis) and the cofactor (NADPH but not $\mathrm{NAD}^{+}$; data not shown) involved in the reduction of MP to MPOL, these data suggest that GA inhibits the $11 \beta-H S D 1-$ dependent reduction in these subcellular fractions of the liver and testis. Therefore, we then investigated the issue of whether the plasma pharmacokinetics of MP and its metabolites were modulated by the co-administration of GA with MP in invivo rat study.

Lin et al. reported that the pharmacokinetics of cortisone and its active metabolite, cortisol, are modulated by three doses daily of GA [18]. We used the same dose and regimen to evaluate the effect of co-administration of GA on the pharmacokinetics of MP and its metabolites. Interestingly, the co-administration of GA caused a rapid and significant decrease in the plasma concentration of MPOL after MP dosing, resulting in the $\mathrm{C}_{\max }$ and $\mathrm{AUC}_{6 \mathrm{~h}}$ of MPOL after MP with a GA dose to be twice lower than the values in the case for MP alone (Figure 4B and Table 1). The decrease in the parameters suggests that $11 \beta$-HSD 1 is inhibited by GA. On the other hand, the plasma MPOL levels after $4 \mathrm{~h}$ were almost the same levels as those for MP alone (Figure 4B). This observation is consistent the rapid disappearance of $11 \beta$-HSD1 inhibition effect by GA $[18,19]$, and implies that the inhibitory effect against the MP reduction by the co-administration of GA had a relatively short life time invivo. In contrast to the MPOL profiles, the plasma concentration of MP was significantly increased at $2 \mathrm{~h}$ after the MP dose by the co-administration of GA, resulting in around a two times increase in the $\mathrm{C}_{\max }$ and $\mathrm{AUC}_{6 \mathrm{~h}}$ for MP (Figure 4A and Table 1). In addition, the co-administration of GA extended the $t_{1 / 2}$ of MP in plasma (Table 1). These results suggest that the reduction and pharmacokinetics of MP are affected by coadministration of GA as with those of a glucocorticoid, and that $11 \beta$-HSD 1 is involved in the reduction of MP in rats. Furthermore, the plasma pharmacokinetics of MPOL NOII and MP NOII were also modulated by the co-administration of GA. A significant decrease was immediately observed in the plasma levels of MPOL NOII after MP with a GA dosing, similar to that which was observed in MPOL, resulting in a lowering in the $\mathrm{C}_{\max }$ and $\mathrm{AUC}_{6 \mathrm{~h}}$ values around half of those after MP alone (Figure 5A and Table 2). On the other hand, a significant increase was observed in the plasma concentration of MP NOII from 2 to $4 \mathrm{~h}$ after MP with the GA dose, resulting increase in the $\mathrm{C}_{\max }$ and $\mathrm{AUC}_{6 \mathrm{~h}}$ of 2 and 1.6 times, respectively, compared with MP alone (Figure 5B and Table 2). Since MP NOII production was inhibited by a CYP inhibitor (ketoconazole and quercetin) [11], the CYP-dependent oxidation of MP would become dominant, due to the inhibition of $11 \beta-H S D 1$ by GA. Contrary to the invivo results, the production of MP NOII in the microsomal and mitochondrial fractions of the liver and testis were not enhanced by the addition of GA to the reaction system in the invitro study (data not shown). Therefore, the increase in the plasma MP NOII concentration can be attributed to drug-drug interactions in the subcellular fractions of other tissues. Regardless of the significant increase in the MP NOII plasma concentration by MP as the result of the GA dose, MP plasma concentration was also significantly increased. The discrepancy indicates that the ratios of MPOL and MPOL NOII production inhibition were higher than that for the increase in MP NOII production. When the abundance ratio and sum of the plasma concentrations of MP and its metabolites were calculated at each sampling point in the absence and presence of GA dose, there were 
Citation: Murata H, Higuchi T, Otagiri M. Invitro and Invivo Inhibition of Metyraponemetabolism by Glycyrrhetinic Acid in Male Wistar Rats. J Pharmaceu Pharmacol. 2016;4(1): 6.

no significant differences in the sum of concentrations at any sample point, and the decrease in the ratios of MPOL and MPOL NOII concentrations were higher than the increase in the ratio of MP NOII by MP with the GA dose (Figure 4B, 5A and 5B). These may be due to the fact that no apparent decrease was observed in the MP plasma concentration. In previous report, we proposed that MPOL NOII was produced via MPOL but not MP NOII, because MPOL was the major metabolite in plasma, but was excreted only small amounts in urine and MPOL NOII was the major metabolite in urine [11]. The changes in the plasma concentration profiles of MPOL and MPOL NOII in the case of co-administration of GA seemed to support this hypothesis. In addition, this proposed metabolic pathway was the same as that reported by Martini et al. [20]. To predict drug-drug interaction that might be effected in humans, the MP metabolites produced in invivo were estimated based on the proposed pathway. Since MPOL and MP NOII were produced in the liver subcellular fractions of humans [11], MPOL NOII would also be expected to be produced in humans invivo. Therefore, the co-administration of MP with an 11ß-HSD1inhibiting drug may affect the pharmacokinetics of MP and its three metabolites (MPOL, MPOL NOII and MP NOII) in humans. Regarding the pharmacological activity, although MPOL is the active metabolites with the same activity as MP in humans [21], the plasma concentration was significantly decreased by GA, contrary to the significant increase of MP plasma concentration. In addition, there is no information that MPOL NOII and MP NOII have the activity. Considering that the extensive difference was not observed in the sum of $\mathrm{AUC}_{6 \mathrm{~h}}$ of MP and MPOL between MP alone and GA combination, even though the pharmacokinetics of MP and its metabolites were modified by $11 \beta$-HSD1 inhibitor, suggesting a low potential to affect the pharmacological activity of MP. Recently, drugs which inhibit $11 \beta-H S D 1$ have been developed to treat obesity [22-24]. From the present evidence, it would be expected that the administration of MP with an 11ß-HSD1-inhibiting drug to humans may modulate the pharmacokinetics of MP and its metabolites. Consequently, our results represented the useful information for predicting the drugdrug interaction in humans.

\section{Conclusions}

The findings of this study demonstrate that GA inhibits the reduction of MP to MPOL at the low concentrations in the microsomal and mitochondrial fractions of, not only the liver but also the testis in male Wistar rats, suggesting that $11 \beta-\mathrm{HSD} 1$ contributes to MP reduction. Based on the variation in the plasma pharmacokinetics of MP and its metabolites by the co-administration of MP with GA in rats, the findings suggest that an $11 \beta$-HSD1 inhibitor, such as GA, could modulate the pharmacokinetics of this reduction pathway.

\section{References}

1. Tomlinson JW, Walker EA, Bujalska IJ, Draper N, Lavery GG, et al. (2004) $11 \beta$-hydroxysteroid dehydrogenase type 1 a tissue-specific regulator of glucocorticoid response. Endocr Rev 25: 831-866.

2. Hoffmann F, Maser E (2007) carbonyl reductases and pluripoten hydroxysteroid dehydrogenases of the short-chain dehydrogenase/reductase superfamily. Drug Metab Rev 39: 87-144.

3. Hult M, Jörnvall H, Oppermann UC (1998) Selective inhibition of human type 11 beta-hydroxysteroid dehydrogenase by synthetic steroids and xenobiotics. FEBS Lett 441: 25-28.

4. Mazzocchi G, Rossi GP, Neri G, Malendowicz LK, Albertin G, et al. (1998) 11 beta-hydroxysteroid dehydrogenase expression and activity in the human adrenal cortex. FASEB J 12: 1533-1539.
5. Ricketts ML, Verhaeg JM, Bujalska I, Howie AJ, Rainey WE, et al (1998) Immunohistochemical localization of type $111 \beta$-hydroxysteroid dehydrogenase in human tissues. J Clin Endocrinol Metab 83: 1325-1335.

6. Maser E, Völker B, Friebertshäuser J (2002) 11 Beta-hydroxysteroid dehydrogenase type 1 from human liver: dimerization and enzyme cooperativity support its postulated role as glucocorticoid reductase. Biochemistry 41: 2459-2465.

7. Seckl JR, Walker BR (2001) Minireview: 11beta-hydroxysteroid dehydrogenase type 1- a tissue-specific amplifier of glucocorticoid action. Endocrinology 142: 1371-1376.

8. Kannisto K, Pietiläinen KH, Ehrenborg E, Rissanen A, Kaprio J, et al. (2004) Overexpression of 11 beta-hydroxysteroid dehydrogenase- 1 in adipose tissue is associated with acquired obesity and features of insulin resistance: studies in young adult monozygotic twins. J Clin Endocrinol Metab 89: 4414-4421.

9. van Rossum EF, Lamberts SW (2006) Glucocorticoid resistance syndrome: a diagnostic and therapeutic approach. Best Pract Res Clin Endocrinol Metab 20: 611-626.

10. Monaghan PJ, Owen LJ, Trainer PJ, Brabant G, Keevil BG, et al. (2011) Comparison of serum cortisol measurement by immunoassay and liquid chromatography-tandem mass spectrometry in patients receiving the $11 \beta$-hydroxylase inhibitor metyrapone. Ann Clin Biochem 48: 441-446.

11. Murata H, Higuchi T, Otagiri M (2016) Oral pharmacokinetics and in-vitro metabolism of metyrapone in male rats. J Pharm Pharmacol 68: 970-979.

12. Rosemond MJ, Walsh JS (2004) Human carbonyl reduction pathways and a strategy for their study in vitro. Drug Metab Rev 36: 335-361.

13. Testa B, Jenner P (1981) Inhibitors of Cytochrome P-450s and their mechanism of action. Drug Metab Rev 12: 1-117.

14. Shaw PN, Tseti J, Warburton S, Adedoyin A, Houston JB (1986) Inhibition of antipyrine metabolite formation. Steady state studies with cimetidine and metyrapone in rats. Drug Metab Dispos 14: 271-276.

15. Arampatzis S Kadereit B, Schuster D, Balazs Z, Schweizer RA, et al. (2005) Comparative enzymology of 11beta-hydroxysteroid dehydrogenase type 1 from six species. J Mol Endocrinol 35: 89-101.

16. Lin D, Sun W, Wang Z, Chen LG, Chen XL, et al.(2012) The effect of glycyrrhetinic acid on pharmacokinetics of cortisone and its metabolite cortisol in rats. J Biomed Biotechnol 2012: 856324

17. Diederrich S, Grossmann C, Hanke B, Quinkler M, Herrmann M, et al. (2000) In the search for specific inhibitors of human 11 beta-hydroxysteroiddehydrogenases (11beta-HSDs): chenodeoxycholic acid selectively inhibits 11 beta-HSD-I. Eur J Endocrinol 142: 200-207.

18. Smith PK, Krohn RI, Hermanson GT, Mallia AK, Gartner FH, et al. (1985) Measurement of protein using bicinchoninic acid. Anal Biochem 150: 76-85.

19. Marandici A, Monder C (1993) Inhibition by glycyrrhetinic acid of rat tissue 11 beta-hydroxysteroid dehydrogenase in vivo. Steroids 58: 153-156.

20. Martini R, Murray M (1996) Characterization of the invivo inhibition of rat hepatic microsomal aldehyde dehydrogenase activity by metyrapone. Biochem Pharmacol 51: 1187-1193.

21. Meikle AW, West SC, Weed JA, Tyler FH (1975) Single dose metyrapone test: 11 beta-hydroxylase inhibition by metyrapone and reduced metyrapone assayed by radioimmunoassay. J Clin Endocrinol Metab 40: 290-295.

22. Byun SY, Shin YJ, Nam KY, Hong SP, Ahn SK (2015) A novel highly potent and selective 11ß-hydroxysteroid dehydrogenase type 1 inhibitor, Ul-1499. Life Sci 120: 1-7.

23. Hamilton BS, Himmelsbach F, Nar H, Schuler-Metz A, Krosky $P$, et al. (2015) Pharmacological characterization of the selective 11ß-hydroxysteroid dehydrogenase 1 inhibitor, $\mathrm{BI}$ 135585, a clinical candidate for the treatment of type 2 diabetes. Eur J Pharmacol 746: 50-55.

24. Chen XQ, Shao LD, Pal M, Shen Y, Cheng X, et al. (2015) Hupehenols A-E, selective 11ß-hydroxysteroid dehydrogenase type 1 (11ß-HSD1) inhibitors from Viburnum hupehense. J Nat Prod 78: 330-334. 